International Journal of Instruction e-ISSN: 1308-1470 • www.e-iji.net
July $2018 \bullet$ Vol.11, No.3

p-ISSN: 1694-609X

pp. 233-248

Received: $13 / 12 / 2017$

Revision: 03/03/2018

Accepted: 10/03/2018

\title{
Influence of Psychosocial Factors on Job Performance of Female Teachers in Kwara State, Nigeria
}

\author{
Aminat Adeola Odebode \\ $\mathrm{PhD}$, Department of Counsellor Education, University of Ilorin, Nigeria, \\ odebode.aa@unilorin.edu.ng
}

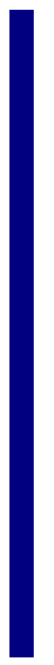

This study focused on the influence of psychosocial factors on job performance of female teachers in Kwara State, Nigeria. The study also examined the variables of age, level of education and length of years in service. The descriptive survey was adopted for the study. A total sample of 400 respondents was selected in Kwara State, using the simple random and purposive sampling techniques. Data were collected using a researcher-designed instrument titled "Influence of Psychosocial Factors on Job Performance Questionnaire" (IPFJPQ). The reliability was ascertained through a test re-test reliability method; this yielded a coefficient of 0.60. ANOVA statistical method was used to analyze the data at 0.05 alpha level. The findings are that the influence of psychosocial factors on job performance of female teachers in Ilorin metropolis is negative; there is no significant difference in the hypotheses tested based on age but, significant differences were found based on level of education, and length of years in service. It was therefore recommended that female teachers should adopt rational management strategies to handle psychosocial factors to improve their job performance. Counsellors should orientate teachers on how to adopt positive approach towards management of psychosocial factors.

Keywords: influence, psychosocial factors, job performance, female teachers, Kwara State

\section{INTRODUCTION}

Teachers are known for their constructive effort towards interpreting government policies on education, and putting the features of the policies into practical measures for assessment (Farrant, 2004; Nakpodia, 2011). Teaching job in the 21st century is a different phenomenon; never could learning be happening the way it is happening now, learning can take place anywhere, any time on any possible topic, supporting any possible learning style or preference. The 21st century teachers are expected to learn modern technologies, keep learning, be smart and use smart phones, go global, go social and build positive digital foot print. In this era of globalization and technological

Citation: Odebode, A. A. (2018). Influence of Psychosocial Factors on Job Performance of Female Teachers in Kwara State, Nigeria. International Journal of Instruction, 11(3), 233-248. https://doi.org/10.12973/iji.2018.11317a 
revolution, education is considered as a first step for every human activity. It plays a vital role in the development of human capital and it is linked with an individual's wellbeing and opportunities for better living (Battle \& Lewis, 2002). Schools in the $21^{\text {st }}$ century become very important to supporting the rapid developments of individuals to perform a wide range of new structural, social, political, cultural and educational functions (Daniels, Beesley, Cheyne \& Wimalasiri, 2008). However, rapid developments of individuals cannot be devoid of stress.

Individuals face stress in many areas of life. Everyone is exposed to stress in the workplace, but some are often and more intensely exposed than others. Stress experienced by teachers is a subject of intense interest in recent years. Numerous factors have been identified as having linked with teacher's occupational stress. The most important of these factors are: teaching requirements, many different activities within the school environment, lack of professional recognition, discipline problems in the classroom, bureaucracy, lack of support, workload, time pressure, lack of benefits (Mearns \& Chain, 2003).

A vast quantity of literature has demonstrated that psychosocial factors at work contribute to a wide range of workers' health disorders. A large amount of evidence has accumulated on the relationship between non-specific psychological, behavioural and somatic syndromes and stressful or unrewarding job conditions. In Nigerian society, both work and living environments can be major sources of adverse psychosocial factors which result in stressful experiences. Adverse occupational psychosocial factors, however, have become increasingly significant. They have been defined as those psychological and social characteristics of the work environment which pose a threat to the individual.

Psychosocial factors such as personality, motivation, social interaction skills, family structure, stress, physical health, self-concept, mental health and environmental condition have been widely acknowledged as being pertinent to job performance of any teacher. Moreover, teaching job in this twenty first century is more arduous than it used to be, especially for female teachers. Female teachers have more to deal with than male teachers. Some research findings attest to the fact that women are more prone to stress than men. For instance, Arroba and James (2002) reported that the relationship between gender and stress is complex and varied and that women are more affected by stress than men. In the same vein, Melhinsh (1998) and Philips and Segal (1996) concluded that since most women work longer hours than men and both do not share duties equally at home, therefore women tend to experience more psychological symptoms of occupational stress than men.

Psychosocial factors are elements that impact employees' psychological responses to work and work conditions, potentially causing psychological health problems. Psychosocial factors include the way work is carried out (deadlines, workload, work methods) and the context in which work occurs (including relationships and interactions with managers and supervisors, colleagues and co-workers, and clients or customers). It is pertinent to note that some of the major sources of stress among female teachers include: age, number of students in the classroom, marital status, work environment, 
workload, appreciation and assessment through supervision. According to Blonna (2005), men and women are stressed trying to balance the demands of husbands or wives, mothers or fathers, children or other relatives. However, women are known to bear the major share of both home and work-related stress. To the researcher, this is because of the preponderant roles women play at work and home. Moreover, factors such as long hours at work, engaging in co-curricular activities, taking care of children and other domestic activities at home, making attempt to further education through distance learning programmes, control and management of both human and financial resources are some principal sources of stress which increase the level of burnout among female teachers.

Culture can be said to be the complexity of different spiritual, material and intellectual features that characterize a group of people in a society. Culture includes arts and letters, modes of life, value systems, traditions and beliefs. It guides the role of both gender in any gender society. Gender role in culture paved way for gender inequality and marginalization of women in patriarchal societies like Nigeria. The traditional perceptions of women as inferior to men also continue to prevail as many people invoke the preservation of African culture to justify the subordination of women. African culture suggests sub-ordinate role for women and leading to male dominance. No wonder, women in Nigeria are made to bear domestic responsibilities alone; this is even worse for working class women like female teachers. In combining the traditional and contemporary roles, many women find themselves playing the roles as wives, mothers, reverend ministers, ministers in politics, chief justices at the supreme court, speakers of parliament, doctors, lawyers, farmers, traders, judges, secretaries, nurses, teachers among others at the same time (Antoniou, Ploumpi \& Ntalla, 2013). All these could culminate into psychosocial factors that could affect female teacher's performances at work.

Psychosocial factors such as female teacher personality, emotions, work experiences, roles and responsibilities to husband and family, in one way or the other might make her accumulate stress and burnout which will certainly influences job performance. Psychosocial workplace risk factors refer to individual subjective perceptions by workers regarding aspects of the organization of work and carry emotional value, for example perceived job demands and degree of support from managers or coworkers. Work organization factors describe characteristics of the work system, for example hours worked, work-rest cycles, culture, management style etc. and have the potential for causing physical or psychological damage to health. These are not globally accepted definitions but are considered suitable for the purposes of this report. Work organization and psychosocial workplace risk factors have been included in the revised guidance on upper limb disorders in the workplace by the HSE (Health and Safety Executive, 2002). Based on an extensive review of the literature, work organization and psychosocial workplace risk factors have been grouped into the following categories (Fernet, Guay, Senectal \& Austin, 2012).

Things are not stagnated, there is much automation in the world of work, times have changed, and the societies and cultures have drastically diversified, but the tasks of a 
teacher have taken new facet with more emphasis on the child, though the tasks are primarily the same, which is the transfer of knowledge to the next generation. With change in cultural norms and traditions in the societies there has been a drastic change in the expectations from a teacher. Teachers in the era of rapid change are often required to take up expanded roles and responsibilities (Tnetteman \& Punch, 2005). Some of these changes have limited the measures which a teacher in the past could exercise in disciplining a student and some have put additional burden on teachers in respect their preparation of lessons and adopting and maintaining their teaching styles. In all education system, the performance of teachers is one of the handfuls of factors determining school effectiveness and learning outcomes. It is commonly accepted that the teachers are the key element for the success of school education (Tsiakkiros, \& Pasiardis, 2002). Teachers are the interpreters of all and any educational plan and philosophy (Anuforo, 2007; Nakpodia, 2011; Lingard, Hayes, \& Mills, 2003). The knowledge that teachers are responsible for thousands of lives in it creates stress. Teachers are responsible for the planning, teaching, and making of course material, in addition to meeting with parents and writing reports, teacher also deal with time pressure and heavy workloads.

There is evidence to suggest that teachers perceive their jobs as more stressful than other comparable professionals like nurses, and studies have shown that up to one third of teachers' report experiencing prominent levels of stress (Travers, 2001). Psychological factors refer to the psychological and social factors that may or mar the performance or output of a teacher in and out of school. According to Antoniou, Ploumpi and Ntalla (2013), it is no surprise that workplace stress is a bigger problem today than even 10years ago. In the 1990's the term work-life balance was coined to describe the solution for being able to "have it all" and manage it with ease.

Job performance is a term that is commonly used, yet poorly defined concept in industrial and organizational psychology, the branch of psychology that deals with the workplace. It most commonly refers to whether a person performs their job well or not. Despite the confusion over how it should be exactly defined, performance is an extremely important criterion that relates to organizational outcomes and success. Among the most commonly accepted theories of job performance comes from the work of John P. Campbell and colleagues. Coming from a psychological perspective, Campbell describes job performance as an individual level variable. That is, performance is something a single person does. This differentiates it from more encompassing constructs such as organizational performance or national performance which are higher level variables (Campbell, 1990). It on this premise basically, that this study focused on influence of psychosocial factors on job performance of female teachers in Kwara State, Nigeria.

A theoretical model which has been in existence for a considerable amount of time, and which to a considerable extent has underpinned other approaches to stress and wellbeing, is the Person-Environment Fit (P-E fit) perspective. This account of the stress process stems from the early work and theorizing of Lowe and Bennett (2003) and Murray (1938). For example, reacting to prevailing mechanistic views of human 
behaviour which attributed the causes of behaviour solely to the environment, and psychodynamic approaches which tended to conceive behaviour as emerging from personality characteristics (traits), Lewin conceptualized the interaction between the person and environment $(\mathrm{P} \times \mathrm{E})$ as the key to understanding people's cognitive, affective and behavioural reactions. His early thinking therefore provided the foundation for the modern perspective of $\mathrm{P}-\mathrm{E}$ fit. He foreshadowed the notion that optimal fit between the person and his/her environment is needed for effective human functioning.

Numerous descriptions of $\mathrm{P}-\mathrm{E}$ fit are available in the literature, although perhaps the most comprehensive account is that offered by Edwards (1998), who also described earlier constructions of P-E fit, such as those initiated by Ferguson, Frost and Hall (2002) The researcher does not attempt to provide an exhaustive account of this theory and its applications but only to summarize the main elements of this perspective, and illustrate how it has been applied. It should also be noted that the tenets of P-E fi t theory also underlie several other theoretical models of stressor-strain relationships, including the cybernetic theory (Cummings \& Cooper, 1979, 2000; Edwards, 1998, Dewe, O'Driscoll \& Cooper, 2012), which will not be discussed. One specific advantage of the $\mathrm{P}-\mathrm{E}$ fi $\mathrm{t}$ conceptualization over some other (more specific) theories is that $\mathrm{P}-\mathrm{E}$ fit is based essentially on the idea of employee adjustment in the work setting, which has been illustrated as being critical for overall well-being (Dawis \& Lofquist, 1984). The notion of "fit" itself has synonyms such as "match," "congruence," and "correspondence."

In the occupational stress and well-being literature, the fit concept has been characterized as having two components: (a) the degree of match, congruence, or correspondence between the demands people confront at work and their abilities to meet those demands, referred to as demands-ability fit; and (b) the match, congruence or correspondence between the person's needs (including physical and psycho-social needs) and the resources available to him/her (Dewe, O'Driscoll \& Cooper, 2012). The latter is referred to as needs-supplies fit. Most research on the relationship between P-E fit and stress or well-being has focused on the second of these types of fi $t$, as it is assumed that a lack of fit (that is, misfit) between needs and resources will have a pronounced impact on stress levels and overall well-being. However, demands-ability fi $\mathrm{t}$ can also be important in terms of a person's well-being. For instance, if person's workload is high and they do not have the time or energy to perform what is expected from them, this can induce a prominent level of psychological strain. A (very simplified) depiction of the basic theory relating to $\mathrm{P}-\mathrm{E}$ fit is provided in Fig.1. The theory hinges on the amount of a "stimulus" (for example, workload, work complexity, level of authority, and social interaction with work colleagues) that an individual prefers, and the actual level of the various stimuli.

There are two conditions in which the level of fit is high: when the preferred levels and the received levels are both high; or when they are both low. Consider, for instance, the level of social contact people has with their work colleagues. An individual may wish to have an extensive amount of contact with colleagues, and may experience this amount. This situation clearly is one where there is a strong match between what people want 
and what they receive; that is a strong fi $\mathrm{t}$, and they should (at least theoretically) experience low strain (and high psychosocial well-being) (Dewe, O'Driscoll \& Cooper, 2012). Alternatively, the individual may not actually want very much contact at all with work colleagues, and does not have substantial interpersonal contact. Again, this situation reflects a high degree of fit, and one might expect the levels of strain to be low. However, this situation is not as clear-cut as the high-high condition, because here social interaction may not be important for individuals and other factors may have more impact on their stress and well-being levels.

Conversely, P-E fit theory postulates that high strain will occur when there is a mismatch between the person's needs and what they receive or confront at work. The condition which (theoretically) should create highest levels of strain will be one where the person strongly desires a feature (such as interpersonal contact), but does not receive it (the high-low box in Fig. 1). Under these circumstances, strain will be at its highest level. On the other hand, when people do not have a strong preference for an attribute (in this case, interpersonal

\section{Preferred}

\begin{tabular}{l|l|l|}
\multicolumn{1}{c}{ High } & \multicolumn{2}{c}{ Low } \\
\cline { 2 - 3 } High & Low Strain & High Strain \\
Low & Low Strain \\
\cline { 2 - 3 } & High Strain & Received
\end{tabular}

Fig. 1

Levels of psychological strain predicted by P-E Fit theory, Source: Dewe, O’Driscoll \& Cooper (2012)

contact), but they do receive it, there is some ambiguity over whether this situation will be stressful for them. They should experience strain, as there is a mismatch between their preference and what they are supplied with (Dewe, O’Driscoll \& Cooper, 2012). However, this is likely to depend on numerous other factors, including whether the attribute interferes with other activities or things the individual would prefer to be engaged in. For instance, having frequent contact with work colleagues may distract the person from core job activities, leading to frustration and a sense of lack of achievement, in which case high strain might be anticipated. In contrast, even though they may not desire it, interpersonal contact may serve as a welcome distraction from a challenging task; hence, they may not feel stressed by it. In sum, although the P-E fit model predicts that misfit (of either kind) will increase levels of strain, in practice the amount of strain experienced in the high-low condition in Fig.1 may be substantially greater than that felt in the low-high situation.

As noted above, increased psychological strain and decreased psychosocial well-being are two major outcomes of misfit in the work context. Other potential outcomes have also been identified in the literature, including job dissatisfaction, reduced commitment 
to the organization, and greater turnover intentions. It is also evident that the notion of $\mathrm{P}-\mathrm{E}$ fit is relevant across various domains, including life outside of work. For the purposes of this chapter, however, we concentrate on its relationship with work-related strain and well-being. Numerous studies have confirmed that misfit (mainly in respect of needs-supplies, but also in terms of demands-abilities) can have grave consequences for worker well-being. A good illustration of this relationship comes from a recent study by Yang, Hongsheng and Spector (2008). These researchers explored the actual and preferred conditions at work, with respect to two key issues-career advancement and relationships at work-in a sample of Chinese workers. Expectations concerning career development are clearly salient to many employees, and opportunities for advancement within their career are typically important. Yang and colleagues hypothesized that correspondence between the preferred level of career advancement and perceptions of opportunities available to employees would enhance job satisfaction, mental and physical well-being, whereas misfit between preferred levels and perceived opportunities would predict reductions in these criterion variables. A similar prediction was proffered by Yang and colleagues in relation to social relationships at work. They suggested that maintenance of harmonious social relationships is a critical need (perhaps even more so in a collectivist culture such as China), and that good social relationships will enable people to fulfil their need for affiliation and need for belonging (Dewe, O’Driscoll \& Cooper, 2012).

There have been many studies on teacher job satisfaction and job performance which has prescribed interventions to address the challenges. However, despite the efforts to addressing these challenges, the teaching force is lethargic and uninterested in assisting learners to acquire the basic knowledge and competencies for the future and career development. This study aims at contributing to the knowledge of influence of psychosocial factors on job performance of female teachers in Kwara State, Nigeria.

\section{Research Questions}

The following research questions were structured for this study:

1. What influences do psychosocial factors have on job performance of female teachers in Kwara State?

2. Is there any difference in the influence of psychosocial factors on job performance of female teachers in Kwara State based on age?

3. Is there any difference in the influence of psychosocial factors on job performance of female teachers in Kwara State based on level of educational attainment?

4. Is there any difference in the influence of psychosocial factors on job performance of female teachers in Kwara State based on length of years in service?

Hypotheses

The following null hypotheses were formulated to guide the conduct of this study.

1. There is no significant difference in the influence of psychosocial factors on job performance of female teachers in Kwara State based on age. 
2. There is no significant difference in the influence of psychosocial factors on job performance of female teachers in Kwara State based on level of educational attainment.

3. There is no significant difference in the influence of psychosocial factors on job performance of female teachers in Kwara State based on length of years in service.

\section{METHOD}

\section{Research Design}

The descriptive design of the survey type was adopted for the study. This type of design is concerned with describing, recording, analyzing and interpreting existing conditions. Daramola (2006) defined descriptive research as systematic attempt to describe the characteristics of a given population or areas of interest factually. The design was considered appropriate because it enabled the researcher to describe the existing influence of psychosocial factors on job performance of female teachers in Kwara State.

\section{Participants}

The population for this study consisted of all senior secondary school teachers in Ilorin south. The sample consisted of female secondary school teachers in Ilorin metropolis. Simple random sampling procedure was used to select ten secondary schools in Ilorin Metropolis. The simple random sampling procedure was also used to select forty (40) female teachers in the selected secondary schools. This made a total of four hundred female teachers that participated in the study.

\section{Data Collection Tools}

The research instrument for this study was a researcher-designed questionnaire tagged "influence of psychosocial factors on job performance of female teachers' questionnaire" (IPFJPFTQ). The instrument comprised two sections, that is section A and section B. The first section sought information about the demographic data of the respondents such as age, level of educational attainment, length of years in service, while section B contained items on the psychosocial factors that influence job performance of female teachers. The instrument was designed to obtain responses from respondents using four-point Likert-type rating scale format of Strongly Agree, Agree, Disagree and Strongly Disagree.

The instrument (questionnaire) was validated by experts in counselling and adult education while the reliability of the questionnaire was determined through test re-test method. The set of scores were subjected to PPMC and a reliability co-efficient of 0.60 was obtained indicating that the instrument is reliable for use.

The instrument was personally administered by the researcher on four hundred (400) respondents.

\section{Data Analysis}

The data collected were analysed by the researcher using both descriptive and inferential statistical procedures. Percentage was used to describe the demographic data. Mean and rank order was used to answer the main research question while Analysis of Variance (ANOVA) was used to test all the null hypotheses at 0.05 alpha level. 


\section{FINDINGS}

Table 1

Mean and rank order of the psychosocial factors experienced by female teachers in Ilorin Metropolis

\begin{tabular}{llll}
\hline Item No. & I experience the following psychosocial factors: & Yes\% & No\% \\
\hline 3 & Having to do house chores alone & 96.0 & 4.0 \\
6 & Matching home with teaching workload & 92.0 & 8.0 \\
2 & Having to meet deadlines at work and home & 90.0 & 10.0 \\
1 & Inability to exercise & 86.0 & 14.0 \\
10 & Having to write daily lesson plan & 80.0 & 20.0 \\
7 & Having to use different teaching method & 72.0 & 28.0 \\
9 & Low income & 66.0 & 34.0 \\
4 & Feeling unhappy most times & 62.0 & 38.0 \\
5 & Coping with numerous challenges of students & 60.0 & 40.0 \\
8 & Having to develop on the job without support & 58.0 & 42.0 \\
\hline
\end{tabular}

Table 1 shows that female teachers experienced psychosocial factors such as having to do house chores alone, matching home with teaching workload, having to meet up with deadline at work and home, inability to exercise, having to write daily lesson plan, having to use different teaching method, having to develop on the job without support among other psychosocial factors.

Research Question 1: What influence do psychosocial factors have on job

Table 2 performance of female teachers in Ilorin metropolis?

Mean and rank order of influence of psychosocial factors on job performance of female teachers in Ilorin metropolis

\begin{tabular}{llll}
\hline Item No. & At work: & Mean & Rank \\
\hline 8 & I am often being physically exhausted & 3.49 & $1^{\text {st }}$ \\
12 & I feel I am not able to cope with teaching workload & 3.23 & $2^{\text {nd }}$ \\
9 & I am not able to meet up with deadlines & 3.20 & $3^{\text {rd }}$ \\
3 & I rarely get involved in extracurricular activities in school & 3.16 & $4^{\text {th }}$ \\
11 & I often become emotionally exhausted & 3.16 & $4^{\text {th }}$ \\
20 & I know I at times adopt poor teaching method & 3.11 & $6^{\text {th }}$ \\
17 & I seek for additional sources of income & 3.10 & $7^{\text {th }}$ \\
8 & I often project pent up emotion towards the students & 3.09 & $8^{\text {th }}$ \\
6 & I often get tired of working with students & 3.05 & $9^{\text {th }}$ \\
19 & I feel hostile to go and teach students & 3.05 & $10^{\text {th }}$ \\
4 & Inability to cover syllabus before examination & 3.00 & $11^{\text {th }}$ \\
5 & Finding it to adjust to new method & 2.88 & $12^{\text {th }}$ \\
1 & Sleeping on duty & 2.88 & $12^{\text {th }}$ \\
16 & Lacking concentration at the point of duty & 2.85 & $14^{\text {th }}$ \\
18 & Carefree attitude towards students' discipline & 2.82 & $15^{\text {th }}$ \\
15 & Rarely enrolling for training and seminars & 2.77 & $16^{\text {th }}$ \\
14 & Frequent absenteeism & 2.72 & $17^{\text {th }}$ \\
2 & Frequent lateness to work & 2.72 & $17^{\text {th }}$ \\
13 & Inability to prepare adequate lesson plan & 2.69 & $19^{\text {th }}$ \\
10 & I usually unhappy & 2.49 & $20^{\text {th }}$ \\
\hline
\end{tabular}


Table 2 shows the mean and rank order of the influence of psychosocial factors on job performance of female teachers in Ilorin metropolis. Item 8 which stated, 'being physically exhausted often' with mean score 3.49 ranked $1^{\text {st }}$. Item 12 which stated, 'inability to cope with teaching workload' with mean score 3.23 , ranked $2^{\text {nd }}$. Item 9 which stated 'inability to meet up with deadlines' ranked $3^{\text {rd }}$ with mean score 3.20. Since the cut-off point for taking decision on the influence of psychosocial factors on job performance of female teachers in Ilorin metropolis is 2.50 and 19 out of the 20 items have means scores above the cut-off; this indicated that the influence ofpsychosocial factors on job performance of female teachers in Ilorin metropolis is negative. Female teachers expressed that psychosocial factors influence teachers' job performance such that they are physically exhausted most of the time, unable to cope with teaching workload, sleep on duty, frequently late to work, unable to prepare adequate lesson plan among others.

\section{Hypotheses Testing}

Hypothesis One: There is no significant difference in the influence of psychosocial factors on job performance of female teachers in Ilorin metropolis based on age.

Table 3

Analysis of variance (ANOVA) on influence of psychosocial factors on job performance of female teachers in Ilorin Metropolis based on age

\begin{tabular}{lllllll}
\hline Age & SS & df & MS & Cal.F-value & $\begin{array}{l}\text { Crit. } \\
\text { F-ratio }\end{array}$ & Decision \\
\hline Between group & 25.642 & 2 & 12.821 & 0.37 & 3.00 & Nt. Sig. \\
Within group & 13706.358 & 397 & 34.524 & & & \\
Total & 13732.000 & 399 & & & & \\
\hline
\end{tabular}

Table 3 indicates that the calculated F-value is 0.37 while, the critical F-value is 3.00 Since the calculated F-value of 0.37 is less than the critical F-value of 3.00 at 0.05 level of significance, the hypothesis is accepted. This means that there was no significant difference in the influence of psychosocial factors on job performance of female teachers in Ilorin metropolis based on age.

Hypothesis Two: There is no significant difference in the influence of psychosocial factors on job performance of female teachers in Ilorin metropolis based on level of education.

Table 4

Analysis of variance (ANOVA) on influence of psychosocial factors on job performance of female teachers in Ilorin Metropolis based on level of education

\begin{tabular}{lllllll}
\hline Level of Education & SS & df & MS & Cal.F-value & $\begin{array}{l}\text { Crit. } \\
\text { F-ratio }\end{array}$ & Decision \\
\hline Between group & 76.554 & 3 & 2536.85 & $81.26^{*}$ & 3.00 & Significant \\
Within group & 1295.446 & 396 & 31.23 & & & \\
Total & 13732.000 & 399 & & & & \\
\hline
\end{tabular}

*Significant, $\mathrm{p}<0.05$ 
Table 4 indicates that the calculated F-value is 81.26 while, the critical F-value is 3.00 since the calculated F-value of 81.26 is greater than the critical F-value of 3.00 at 0.05 level of significance, the hypothesis is rejected. This means that there was significant difference in the influence of psychosocial factors on job performance of female teachers in Ilorin metropolis based on level of education. However, a post-hoc analysis Duncan Multiple Range Test (DMRT) was further conducted to identify where the difference lies amongst the variables.

Table 5

Duncan multiple range test (DMRT) output for differences in the influence of psychosocial factors on job performance of female teachers in Ilorin Metropolis based on level of education

\begin{tabular}{lclcl}
\hline Level of Education & Group & Mean & N & Duncan's Grouping \\
\hline Below NCE & 1 & $67.81^{*}$ & 35 & A \\
OND/NCE & 2 & 58.29 & 67 & B \\
B.Sc./B.Ed. & 3 & 53.37 & 60 & C \\
Higher degree & 4 & 54.58 & 38 & D \\
\hline
\end{tabular}

Table 5 shows the Duncan Multiple Range Test (DMRT) output for significant difference in the influence of psychosocial factors on job performance of female teachers' in Ilorin Metropolis based on level of education. The table shows that respondents who have below NCE had 67.81 as the mean score which is significantly different from the mean scores of other levels of education which have mean scores of 58.29, 53.37 and 54.58 respectively. However, group 1 (Below NCE) i.e., female teachers who have below NCE contributed most to the differences shown on table 7.

Hypothesis Two: There is no significant difference in the influence of psychosocial factors on job performance of female teachers in Ilorin metropolis based on level of education.

Table 6

Analysis of variance (ANOVA) on influence of psychosocial factors on job performance of female teachers in Ilorin Metropolis Based on length of years in service

\begin{tabular}{|c|c|c|c|c|c|c|}
\hline Length of Service & SS & $\mathrm{df}$ & MS & Cal.F-value & $\begin{array}{l}\text { Crit. } \\
\text { F-ratio }\end{array}$ & Decision \\
\hline Between group & 2448.272 & 2 & 1224.136 & $21.37 *$ & 3.00 & Significant \\
\hline Within group & 11283.728 & 397 & 57.278 & & & \\
\hline Total & 13732.000 & 399 & & & & \\
\hline
\end{tabular}

*Significant, $\mathrm{p}<0.05$

Table 6 indicates that the calculated F-value is 21.37 while, the critical F-value is 3.00 since the calculated F-value of 81.26 is greater than the critical F-value of 3.00 at 0.05 level of significance, the hypothesis is rejected. This means that there was significant difference in the influence of psychosocial factors on job performance of female teachers in Ilorin metropolis based on length of years in service. However, a post-hoc analysis Duncan Multiple Range Test (DMRT) was further conducted to identify where the difference lies amongst the variables. 
Table 7

Duncan multiple range test (DMRT) output for differences in the influence of psychosocial factors on job performance of female teachers in Ilorin Metropolis based on length of years in service

\begin{tabular}{lclll}
\hline Length of Years in Service & Group & Mean & N & Duncan's Grouping \\
\hline Below 5 years & 1 & $62.37^{*}$ & 30 & A \\
6-10 years & 2 & 58.52 & 63 & B \\
11yrs and above & 3 & 54.03 & 107 & C \\
\hline
\end{tabular}

Table 7 shows the Duncan Multiple Range Test (DMRT) output for significant difference in the influence of psychosocial factors on job performance of female teachers' in Ilorin Metropolis based on length of years in service. The table shows that respondents who have below 5 years had 62.37 as the mean score which is significantly different from the mean scores of other levels of education which have mean scores of 58.52 and 54.03 respectively. However, group 1 (Below 5 years) i.e., female teachers who have spent below 5 years in service contributed most to the differences shown on table 6.

\section{DISCUSSION}

The findings of this study showed that female teachers experienced psychosocial factors such as having to do house chores alone, matching home with teaching workload, having to meet up with deadline at work and home, inability to exercise, having to write daily lesson plan, having to use different teaching method, having to develop on the job without support among other psychosocial factors. The findings of this study also revealed that, female teachers expressed that psychosocial factors influence teachers' job performance such that they are physically exhausted most of the time; unable to cope with teaching workload, sleep on duty, frequently late to work, unable to prepare adequate lesson plan among others. This indicates that the influence of psychosocial factors on job performance of female teachers in Ilorin metropolis is negative. These findings represent a departure from the result of Popoola and Ilugbo (2013). In their findings they asserted that majority of female teachers in Osun State Teaching Service had low level of stress. From the results, $80.3 \%$ of teachers had low stress level while $15.1 \%$ had medium and high stress level.

Another finding of this study revealed that there is no significant difference in the influence of psychosocial factors on job performance of female teachers in Ilorin metropolis based on age. This finding negates that of Fleura, Erika and Naim (2015) which asserted that the levels of stress experienced by teachers in Kosovo are explicable through levels of education and place of residence. Nonetheless, there are complex relationships between several types of stressors and characteristics such as age, working experience, educational level, or place of residence.

Also, the finding of this study revealed that there is significant difference in the influence of psychosocial factors on job performance of female teachers in Ilorin metropolis based on level of education. This finding is consistent with the findings of Beehr, Glaser, Canali and Wallway (2001); Geetika and Harish (2015) that asserted that 
when level of education increases, stress experienced also increases due to increase in the responsibilities. As per educational qualification, the present study reveals that teacher educators vary in their stress level as their educational qualification varies. Less qualified teacher educators feel more stressed than highly qualified teacher educators. This finding is also consistent with the review of previous researches. For instance, Schaufeli, Bakker \& Salanova (2006) also found that people who have low education are more likely to experience elevated level of psychosocial stress and more likely to have negative manifestation of stress than their counterpart.

The finding showed that there is significant difference in the influence of psychosocial factors on job performance of female teachers in Ilorin metropolis based on length of years in service. However, length of years in service is synonymous to work experience; this study reveals that there is significant difference in the influence of psychosocial factors on job performance of female teachers in Ilorin metropolis based on length of years in service. This finding corroborates that of Geetika and Harish (2015) which revealed that there is significant difference in the occupational stress level as the year of experience of teacher educator varies. Less experienced teacher educators are more prone to work stress than highly experienced. Perhaps, the reason for this might be because, less experienced teacher educators do not possess much practical knowledge that can help them to control and adjust their work demands. As a result, they can feel that they are less efficient to perform the roles which makes them to experience higher level of stress.

\section{CONCLUSION AND RECOMMENDATIONS}

Based on the findings from this study, it can be concluded that the influence of psychosocial factors on job performance of female teachers in Ilorin metropolis is negative. Female teachers expressed that psychosocial factors influence teachers' job performance such that they are physically exhausted most of the time, unable to cope with teaching workload, sleep on duty, frequently late to work, unable to prepare adequate lesson plan, rarely involving in extracurricular activities, becoming emotionally exhausted often, seeking for alternative jobs, projecting pent up emotion before the students among others. The finding also revealed that there is no significant in the influence of psychosocial factors on job performance of female teachers in Ilorin metropolis based on age but, significant differences were found based on level of education, and length of years in service. It is therefore recommended that Family members, especially the husband should show an appropriate level of understanding by providing support at all time in taking care of the children and some daily house chores. This could bring relief and reduce physical exhaustion in females. School heads should saddle female teachers with reasonable and bearable workloads to enhance high job performances. Setting deadly and unrealistic deadlines should be avoided at all cost by school administrators.

Appropriate support should be given to female teachers who are willing to further their studies and progress on teaching profession. Government should motivate female teachers who are diligent and committed to work. Motivations such as paying excess workload allowances regularly should be strongly considered. Female teachers should 
create time as much as possible to exercise. It has been widely documented that an average of 30 minutes exercise per day goes a long way in relaxing the body and relieving stress.

\section{Implications for Counselling Practice}

1. Counsellors could organize programmes for women generally to help them wade off psychosocial factors that may lead to stress.

2. Counsellors should help female teachers develop appropriate coping strategies so that they can put in their best in the teaching profession.

3. Counsellors should be advocators of motivating female teachers as this is key in enhancing their job performance.

The family members, particularly husbands can be encouraged to give needed support to their wives.

\section{REFERENCES}

Anuforo, A.M. (2007). Principles and practices of Teaching. Lagos: T-Excel Publishers.

Arroba, T., \& James, K. (2002). Pressure at work: A survival guide (2nd Ed.). Maidenhead: McGraw-Hill.

Antoniou, A.S., Ploumpi, A. \& Ntalla, M. (2013). Occupational stress and professional burnout in teachers of primary and secondary education: The role of coping strategies. Psychology, 14(3A), 349-355 Published Online March 2013 in SciRes. Retrieved, 27 July 2017 from http://www.scirp.org/journal/physc.

Battle, J., \& Lewis, M. (2002). The increasing significance of class: The relative effects of race and socioeconomic status on academic achievement. Journal of Poverty, 6(2), 21-35.

Beehr, T. A., Glaser, K. M., Canali, K. G., \& Wallwey, D. A. (2001). Back to basics: Re-examination of the demand control theory of occupational stress. Work andStress, $15,115-130$

Blonna, R. (2005). Coping with stress in a changing world. 3rd ed. New York: McGraw- Hill books.

Cummings, T. G., \& Cooper, C. L. (1979). Cybernetic framework for studying occupational stress. Minneapolis: Minnesota Press.

Cummings, T. G., \& Cooper, C. L. (2000). A cybernetic theory of organizational stress.In C. L. Cooper (Ed.), Theories of stress (pp. 101-121). Oxford: Oxford University Press.

Daniels, K., Beesley, N., Cheyne, A., \& Wimalasiri, V. (2008). Coping processes linking the demands-control-support model, affect and risky decisions at work. Human Relations, 61 (6), 845-874. 
Dawis, R. V., \& Lofquist, L. H. (1984). A psychological theory of work adjustment.Minneapolis: University of Minnesota Press.

Dewe, P.J., O'Driscoll, M.P, \& Cooper, C.L. (2012). Theories of psychological stress. Retrieved $28^{\text {th }}$ September, from chichester: Wiley-Blackwell.

Edwards, J. R. (1995). Alternatives to difference scores as dependent variables in thestudy of congruence in organizational research. Organizational Behavior and Human Decision Processes, 64, 307-324.

Edwards, J. R. (2000). Cybernetic theory of stress, coping and well-being. In C. L. Cooper (Ed.), Theories of stress (pp. 122-152). Oxford: Oxford University Press.

Farrant, J.S. (2004). Principles and practice of education. Edinbugh: London group limited. LGL publishers.

Fernet, C., Guay, F., Senectal, C., \& Austin, S. (2012). Predicting interindividualchanges in teacher burnout: The role of perceived school environment and motivational factors. Teaching and Teacher Education, 28, 514-525. doi: 10.1016/j.tate.2011.11.013

Fleura S, Erika M, \& Naim F (2015) Workplace Stress Among Teachers in Kosov. SAGE Open October-December 2015: 1-8® The Author(s) 2015DOI: 10.1177/2158244sgo.sagepub.com.

Ferguson, K.; Frost, L.; Hall, D. (2012). Predicting teacher anxiety, depression, and job satisfaction. J. Teach. Learn., 8, 27-42.

Geetika, J. \& Harish, K. T.(2015) Psycho-Social Factors Causing Stress: A Study of Teacher Educators. Journal of Education and Practice www.iiste.org ISSN 2222-1735 (Paper) ISSN 2222-288X (Online)Vol.6, No.4, 2015125.

Lowe, R., \& Bennett, P. (2003). Exploring coping reactions to work stress: applicationof an appraisal theory. Journal of Occupational and Organizational Psychology, 676, 393-400.

Lingard, B., Hayes, D and Mills, M (2003). Teachers and productive pedagogiescontextualizing, utilizing pedagogy. Culture \& Society, 1 (3), 399-424.

Mearns, J., \& Cain, J. E. (2003). Relationships between teachers' occupational stress and their burnout and distress: Roles of coping and negative mood regulation expectancies. Anxiety, Stress and Coping, 16, 71-82. doi:10.1080/1061580021000057040.

Melhinsh, A. (1980). Executive health. London: Business Books.

Murray, H. (1938). Explorations in personality. Boston, MA: Houghton Mif fl in. 
Nakpodia, E. D., (2011). Philosophy as a tool for sustainable development: A contemporary issue in Nigeria educational system. African Journal of Social Sciences, 1(1) 65-74. Retrieved $27^{\text {th }}$ July 2017 from, http://ssrn.com/abstract=1782004.

Popoola, B. I. \& Ilugbo, E. A. (2013). Personality traits as predictors of stress among female teachers in Osun state teaching service. A thesis submitted to theDepartment of Educational Foundations and Counselling, Obafemi Awolowo University Ile Ife, Nigeria.

Simmons, B. L., \& Nelson, D. L. (2007). Eustress at work: Extending the holistic stressmodel. In D. L. Nelson \& C. L. Cooper (Eds.), Positive organizational behaviour (pp. 40-53). London: Sage.

Schaufeli, W. B., Bakker, A. B., \& Salanova, M. (2006). The measurement of work engagement with a short questionnaire: A cross-national study. Educational and Psychological Measurement, 66 (4), 701-716.

Thomas, N., Clarke, V. \& Lavery, J. (2003). Self-reported work and family stress of female primary teachers. Australian Journal of Education, 47 (1), 73 - 87

Tnetteman E, \& Punch K (2005). Teachers' psychological distress: The ameliorating effects of control over the work environment. Edu. Rev. 44(2): 181-194.

Travers, C. (2001). Stress in teaching: past, present, and future: in J. Dunham. Stress in the workplace, past, Present, and future, (pp. 130-162). London: Whurr.

Tsiakkiros, A., \& Pasiardis, P. (2002). Occupational stress of teachers and school principals. Pedagogical Review, 33, 195-213.

Van Horn, J. E., Schaufeli, W. B., \& Taris, T. W. (2001). Lack of re- ciprocity among Dutch teachers: Validation of reciprocity indices and their relation to stress and wellbeing. Work and Stress, 15, 191- 213. doi:10.1080/02678370110066571

Vandenberghe, R. and Huberman, A. M. (1999). Understanding and Preventing Teacher burnout, Cambridge, England.

Yang, L.-Q., Hongsheng, C., \& Spector, P. E. (2008). Job stress and well-being: An examination from the view of person-environment fi t. Journal of Occupationaland Organizational Psychology, 81 (3), 567-587. 